\title{
Overview of current chelation practices
}

\author{
Y. Aydinok \\ Ege University Medical School, Department of Pediatric Hematology, Izmir, Turkey
}

\begin{abstract}
Deferoxamine (DF0) is reference standard therapy for transfusional iron overload since the 1980 s. Although it is a highly effective iron chelator, the compliance problem to subcutaneous administration of DFO remains as the major problem. The oral chelator Deferiprone (DFP) has no marketing licence in North America, however, it has been licensed in India since 1994 and the European Union (EU) granted marketing approval for DFP in 1999, specifically for patients with thalassemia major when DFO is inadequate, intolerable or unacceptable. There are still limited data available on the use of DFP in children between 6 and 10 years of age, and no data on DFP use in children under 6 years of age. Subsequently the oral chelator Deferasirox (DFX) was approved by FDA and EMA for the treatment of patients with transfusional iron overload -older than 2 years of age- as first line therapy, in 2005 and 2006 respectively. The primary objective of iron chelation is to maintain body iron at safe levels at all times but once iron is accumulated, the objective of iron chelation is to reduce tissue iron to safe levels which is a slow process. The chelation regimen, dose and frequency of administration, of the chelator(s) are mainly determined based on body iron burden, presence of myocardial iron and the transfusional iron loading rate. A proper monitoring of chelation is of importance for measuring the response rate to a particular regimen and providing dose adjustments to enhance chelation efficacy and to avoid toxicity. Efficacy of a chelation regimen may exhibit individual variability resulting from factors such as absorbtion and metabolism of the chelator. Tolerability and compliance are also individual variables effecting the response to chelation. Understanding of advantages and limitations of chelators, accurately determining chelation needs
\end{abstract}

Correspondence: Y. Aydinok, Ege University Medical School, Department of Pediatric Hematology, Izmir, Turkey.

Key words: thalassemia, oral chelators.

(c) Copyright Y. Aydinok, 2011

Licensee PAGEPress, Italy

Thalassemia Reports 2011; 1(s2):e10

doi:10.4081/thal.2011.s2.e10

This article is distributed under the terms of the Creative Commons Attribution Noncommercial License (by-nc 3.0) which permits any noncommercial use, distribution, and reproduction in any medium, provided the original author(s) and source are credited.

Parts of this work were presented at the "12th International Conference on Thalassemia and Hemoglobinopathies”, Antalya (Turkey), 11-14 May 2011. of patients with iron overload and designing individualized chelation regimens with less toxicity but optimum efficacy, should provide long-term survival and quality of life for patients with iron loading anemias. The goal of this review is to summarize current concepts in iron chelation therapies based on the considerable amount of prospective data obtained by clinical studies.

\section{Introduction}

It is estimated that globally, 300000 children are born each year with either sickle cell anemia or a form of thalassemia and almost 100 000 patients undergo transfusions. ${ }^{1}$ Regular transfusions in patients with thalassemia major (TM) from infancy have resulted in iron induced liver disease and endocrine complications and are inevitably followed by death from iron induced cardiomyopathy if untreated. ${ }^{2}$ In patients with thalassemia intermedia (TI), increased intestinal iron absorbtion leads to considerable amount of iron accumulation which is ultimately needed iron chelating therapy. ${ }^{3}$ Gradually increasing number of patients with sickle cell disease (SCD) is also being treated with long-term red cell transfusions and requiring chelation therapy. ${ }^{4,5}$ The purpose of this review is to focus on the chelation practices on transfusional iron overload in mainly patients with TM.

\section{Objectives of iron chelation therapy}

The primary objective of iron chelation is to maintain body iron at safe levels at all times but once iron is accumulated, the objective of iron chelation is to reduce tissue iron to the safe levels, which is a slow process particularly in heavily iron loaded subjects. ${ }^{6,7}$ Uncertainties also exist about how quickly total body and tissue iron levels can be safely removed and optimal balance would be established between removal of body iron and avoiding chelator toxicity for varied chelation regimens.

The chelator and dosing regimens (especially if the chelator is DF0) are mainly determined based on body iron burden, the presence of myocardial iron and the transfusional iron loading rate. A proper monitoring of chelation is of importance for measuring the response rate to a chelation regimen and providing dose adjustments to enhance chelation efficacy as well as to avoid toxicity. Efficacy of a chelation regimen may show individual variability resulting from factors such as absorbtion and metabolism of the chelator. Tolerability and compliance with the chelator are also individual variables effecting response to chelation. Understanding of advantages and limitations of chelators, assessing the iron burden of patients accurately and designing individualized chelation regimens with less toxicity but optimum efficacy may provide long-term survival and quality of life for patients with iron loading anemias. 


\section{Properties of iron chelators}

Three chelators are currently in use for the purpose of preventing and removing transfusional iron overload. DF0 is a reference standard therapy since the 1980s and was the only approved chelator until 1999 in Europe, when European Union (EU) granted marketing approval for oral chelator DFP specifically for patients with TM when DFO is inadequate, intolerable or unacceptable. There are still limited data available on the use of DFP in children between 6 and 10 years of age, and no data on DFP use in children under 6 years of age. ${ }^{8}$ Subsequently, DFX as once daily oral chelator was approved by FDA and EMA for the treatment of patients with transfusional iron overload -older than 2 years of age- as first line therapy. ${ }^{9}$

DFO must be administered by prolonged subcutaneous infusion due to its rapid metabolism in plasma $\left(\mathrm{t}_{1 / 2}=20-30 \mathrm{~min}\right)$. It is extremely important to comply with adequate dose of DF0 (20-60 mg/kg/d) at least 5 days a week. Labile plasma iron (LPI) chelated with DFO is eliminated predominantly by the kidneys. ${ }^{10}$ Hepatocytes efficiently take up DFO, which then chelates hepatocellular iron and feroxamine is excreted in the bile. ${ }^{11}$ High molecular weight (MW 559) of hydrophilic DF0 retards its access into the labile cell iron (LCI) pool. ${ }^{12}$ However clinical data showed that siderotic heart failure is reversible with 24 hours intravenous DFO infusion via indwelling catheter and myocardial T2* improves in concert with function during recovery. ${ }^{13,14}$

Oral chelator DFP is a widely used regimen of $75 \mathrm{mg} / \mathrm{kg}$ per day at three divided doses, up to $100 \mathrm{mg} / \mathrm{kg}$. Moderate plasma half life $\left(\mathrm{t}_{1 / 2}=2\right.$ $3 \mathrm{~h}$ ) is required, therefore its administration is at least 3 times a day. Although, LPI is removed by DFP, rebound between doses may occur. ${ }^{10}$ DFP, probably because of the rapid inactivation by glucuronidation within the liver, ${ }^{15}$ shows less impressive effect on liver iron concentrations. ${ }^{16}$ However, it readily enters cells as a small (MW 139) and lipophilic molecule and may access intracellular iron more effectively than DFO. ${ }^{17,18}$ A randomized prospective study suggests that DFP has superior access to myocardial iron stores compared with DFO, which accords with in vitro data. ${ }^{19}$ DFP is excreted predominantly by urine.

DFX at doses of 10 to $40 \mathrm{mg} / \mathrm{kg}$ per day is administered once daily dosing providing 24 -h protection from LPI. ${ }^{10} \mathrm{DFX}$ forms complexes with plasma iron and DFX-iron complexes are eliminated predominantly through a hepatobiliary route. Hepatocytes also readily take up deferasirox, which chelates hepatocellular iron. The DFX-iron complexes are then excreted in the bile. ${ }^{20}$ Invitro studies confirm its rapid access to labile cell iron pools. ${ }^{17,18}$ Continued reduction and normalization of cardiac iron was observed in a long term prospective study of DFX. ${ }^{21}$ DFX is excreted by feces (Table 1 ).

\section{When should chelation be started and what are the safe levels of body iron burden?}

The primary objective of iron chelation therapy is to maintain body iron at safe levels at all times. This has been traditionally determined based on experience with DFO chelation in which intensive chelation at or close to the time when a transfusion program was initiated in effort to prevent iron toxicity resulted with chelator toxicity which particularly appears as impaired growth and skeletal changes. Following this observation, chelation has been started following 10-20 red cell transfusions and when serum ferritin exceeds $1000 \mathrm{ug} / \mathrm{L} .{ }^{22}$ Although this traditional threshold is currently applied to other chelation practices, there is uncertainty whether chelation can be safely started earlier with other chelators or this should be desired.

Chelation therapy should aim to maintain an LIC of about to 3.2-7 $\mathrm{mg}$ iron/g d.w. (normal ranges 0.6-1.2 $\mathrm{mg}$ iron/g d.w.) which was associated with normal survival without complications of iron overload in subjects with non transfusional iron overload. ${ }^{24,} 25$ Maintenance of normal liver iron levels might decrease the likelihood of complications of iron overload but increase chelator toxicity. Although, the serum ferritin levels corresponding to the targeted LIC have not been clearly defined, in practice, serum ferritin is maintained at between 500 and $1000 \mathrm{ug} / \mathrm{L}$. ${ }^{23,}{ }^{24}$ It has also been described that most of the toxic effects of DFO are more likely related with prescribing relatively higher doses of DFO while body iron stores are low. Based on this observation, it has been suggested that a therapeutic index obtained from the ratio of the mean daily dose of DFO (mg/kg) divided by the serum ferritin $(\mu \mathrm{g} / \mathrm{L})$ identifies patients at risk of sensorineural hearing loss, if the ratio is greater than $0.025 .^{25}$ Thereafter, the therapeutic index has been implemented carefully to avoid DFO toxicity. However, it is unknown whether chelator toxicity of DFP or DFX also occurs as low body iron levels fall.

\section{Removal characteristics of excess iron}

The secondary objective of iron chelation therapy is to reduce tissue iron to the safe levels once it is accumulated. The questions are; how quickly total body \& tissue iron levels can be safely removed and normalized?

How optimal balance would be established between effectiveness in removal of excess iron and toxicity of chelator?

Table 1. Properties of iron chelators.

\begin{tabular}{|c|c|c|c|}
\hline $\begin{array}{l}\text { Properties } \\
\text { Chelator iron complex }\end{array}$ & $\begin{array}{c}\text { Deferoxamine } \\
\text { Hexadentate }(1: 1)\end{array}$ & $\begin{array}{c}\text { Deferiprone } \\
\text { Bidentate (3:1) }\end{array}$ & $\begin{array}{c}\text { Deferasirox } \\
\text { Tridentate }(2: 1)\end{array}$ \\
\hline MW, hydro/lipophilic & 559, hydrophilic & 139, lipophilic & 373, lipophilic \\
\hline Usual dose & $20-60 \mathrm{mg} / \mathrm{kg} / \mathrm{d}$ & $75-100 \mathrm{mg} / \mathrm{kg} / \mathrm{d}$ & $10-40 \mathrm{mg} / \mathrm{kg} / \mathrm{d}$ \\
\hline Route & $\begin{array}{l}\text { s.c., i.v. } 8-12 \text { h, } \\
5 \text { days/week }\end{array}$ & oral, tid & oral, od \\
\hline Half-life & 20-30 min & $2-3 \mathrm{~h}$ & $8-16 \mathrm{~h}$ \\
\hline Excretion & urinary, fecal & urinary & fecal \\
\hline Depletion of LPI ${ }^{10}$ & yes (continuous infusion) & yes (rebound between doses) & yes \\
\hline Removal of hepatocellular iron & yes $^{11}$ & less impressive ${ }^{16}$ & yes ${ }^{13}$ \\
\hline Accessing LCI pool & Retard $^{12}$ & rapidly penetrate and bound ${ }^{17,18}$ & rapidly penetrate and bound ${ }^{17,18}$ \\
\hline $\begin{array}{l}\text { Clinical data; extracting LCI in } \\
\text { cardiomyocytes }\end{array}$ & benefits of 24 h i.v. infusion ${ }^{13,14}$ & higher than standard DFO ${ }^{19}$ & in comparison vs DFO \\
\hline
\end{tabular}




\section{Impact of transfusional iron loading rate, chelator dose and regimen on iron removal}

Negative iron balance is defined as excess of iron excreted over that received in form of transfused red cells. In a prospective randomized study comparing DFX with DF0, it has been shown that transfusional iron loading rate has a major impact on the success of a chelator and the percentage of patients achieving negative iron balance, by using any chelator dose, decrease with increasing transfusional iron intake. Further, at an average transfusional iron intake of $0.3-0.5 \mathrm{mg} / \mathrm{kg} / \mathrm{d}$, it has been shown that negative iron balance was achieved in $75 \%$ of patients receiving standard doses of subcutaneous DFO (35-49 $\mathrm{mg} / \mathrm{kg} / \mathrm{d}$ ) 5 days a week, whereas it was achieved in $86 \%$ of patients at greater doses of DFO. DFX at a dose of $20 \mathrm{mg} / \mathrm{kg}$ was able to achieve negative iron balance in $55 \%$ of patients but at dose of $30 \mathrm{mg} / \mathrm{kg}$, negative iron balance was achieved in $83 \%$ of patients (Table 2). ${ }^{26}$

The success of DFP in achieving negative iron balance was also examined in short term iron balance studies. It has been shown that DFP at a dose of $75 \mathrm{mg} / \mathrm{kg}$ achieved negative iron balance in $46 \%$ of patients whereas at dose of $100 \mathrm{mg} / \mathrm{kg}$, negative iron balance was achieved in $86 \%$ of patients. ${ }^{27,28}$ In line with the observation of iron balance study with DFP, in a randomized prospective study, $62 \%$ of TM patients treated with DFP at the dose of $75 \mathrm{mg} / \mathrm{kg}$ showed a decrease in LIC during the study period of one year. However, the addition of subcutaneous standard dose DFO (40-50 mg/kg) only twice weekly to daily DFP therapy resulted with decrease in LIC in almost $90 \%$ of patients which was comparable with those achieved by standard DFO infusions 5 days a week (Table 3 ). In this study, mean transfusional iron intake was measured as $0.25 \mathrm{mg} / \mathrm{kg} / \mathrm{d}$ in patients randomized to DFP and combined therapy arms and $0.20 \mathrm{mg} / \mathrm{kg} / \mathrm{d}$ in those randomized to DFO arm: ${ }^{29}$ It has also been shown that combined therapy of daily DFP and twice weekly DFO resulted with higher ratio of iron excretion to iron intake (negative iron balance) compared to DFP monotherapy or standard DFO therapy given subcutaneously 5 days a week..$^{30,31}$

The prescribed doses of DFX have been selected based on transfusional iron intake in addition to baseline body iron burden in following clinical trials of DFX. The 1 year EPIC study was the largest trial conducted for an iron chelator to evaluate whether fixed starting doses of DFX, based on transfusional iron intake, with dose titration guided by serum ferritin, provides acceptable chelation practice in patients with transfusional iron overload. More than a 1000 TM patients were recruited to the study. At the end of the study, patients receiving higher DFX doses of above $30 \mathrm{mg} / \mathrm{kg}$ at lower transfusional iron intake reflected in significant reduction in serum ferritin, whereas lower DFX doses at higher transfusional iron intake was consistent with maintenance of serum ferritin levels (Table 4). ${ }^{32}$

The 1 year ESCALATOR study in heavily iron loaded patients with TM also confirmed the importance of timely dose adjustments based on serum ferritin trends monitored at monthly intervals for achieving therapeutic target of maintenance or reduction in iron burden by means of LIC in pediatric and adult patients with TM. ${ }^{33}$ Long-term efficacy and safety of DFX has also been evaluated in TM patients aged $\geq 2$ years. Patients who completed a 1-year, Phase III, randomized trial comparing DFX vs. DF0 ${ }^{34}$ entered a 4-year extension study, either continuing on DFX (DFX cohort) or switching from DFO to DFX (crossover cohort). Initial DFX doses were assigned to the patients in both cohorts based on LIC values. During the extension study, dose adjustments of 5 to $10 \mathrm{mg} / \mathrm{kg} /$ day were allowed every 3 months based on trends in serum ferritin and safety parameters. At the EOS, $51.0 \%$ and $42 \%$ of patients in DFX and crossover cohorts achieved serum ferritin levels below 1000 ug/L after at least 4 years of DFX, of whom only 13 and 17\% had serum ferritin below 1000 at baseline. DFX treatment had a dose-dependent effect on LIC with the largest reduction in patients assigned to starting dose of $30 \mathrm{mg} / \mathrm{kg} /$ day at the end of study. ${ }^{35}$

\section{Impact of iron chelators on survival of patients with thalassemia major}

Implementation of DFO chelation at the end of 1970s resulted with a significant improvement in survival of patients with TM who has born after 1970 in a large Italian cohort. However, almost 10\% of patients, who has born after 1970, inevitably developed heart disease which was remained as the most common cause of the death, occurring in more than half of the patients. Compliance problem with the

Table 2. Percentage of patients achieving negative iron balance based on transfusional iron loading rate and chelator dose (Data from Cohen A, et al. Blood 2008; 111:583-7).

\begin{tabular}{lccc} 
DFO (mg/kg) & \multicolumn{3}{c}{ Transfused iron ( $\mathrm{mg} / \mathrm{kg} / \mathrm{d})$} \\
X5/ week & $<0.3$ & $0.3-0.5$ & $>0.5$ \\
$35-49$ & $76 \%$ & $75 \%$ & $52 \%$ \\
$>50$ & $100 \%$ & $86 \%$ & $89 \%$ \\
\hline DFX (mg/kg/d) & & Transfused iron $(\mathrm{mg} / \mathrm{kg} / \mathrm{d})$ & \\
& $<0.3$ & $0.3-0.5$ & $>0.5$ \\
10 & $29 \%$ & $14 \%$ & $0 \%$ \\
20 & $76 \%$ & $55 \%$ & $47 \%$ \\
\hline 30 & $96 \%$ & $83 \%$ & $82 \%$ \\
\hline
\end{tabular}

Table 3. Changes in LIC with different chelation regimens in TM (Data from Aydinok et al. Blood 2006; 108(11): abstract 557).

\begin{tabular}{lccc} 
LIC & DFP $(\mathrm{n}=29)$ & $\mathrm{DFP}+\mathrm{DFO}(\mathrm{n}=24)$ & $\mathrm{DFO}(\mathrm{n}=19)$ \\
$(\mathrm{mg} \mathrm{Fe} / \mathrm{g}$ d.w. $)$ & $\mathrm{n}(\%)$ & $\mathrm{n}(\%)$ & $\mathrm{n}(\%)$ \\
decrease & $18(62)$ & $21(87.5)$ & $17(90)$ \\
maintained & $4^{*}(14)$ & $2^{*}(8.5)$ & $1^{*}(5)$ \\
\hline increase & $7(24)$ & $1(4.0)$ & $1(5)$ \\
\hline
\end{tabular}

*LIC maintained below $7 \mathrm{mg}$ Fe/g d.w. at 1 of 4 in DFP and all in DFP+DFO and DFO arms

Table 4. Change in serum ferritin from baseline by mean accrual dose of DFX (Data from Cappellini MD, et al. Haematologica 2010; 95(4); 557-66).

\begin{tabular}{|c|c|c|c|c|}
\hline Deferasirox doses & $<20 \mathrm{mg} / \mathrm{kg}(\mathrm{n}=231)$ & $\geq 20-<30 \mathrm{mg} / \mathrm{kg}(\mathrm{n}=732)$ & $\geq 30 \mathrm{mg} / \mathrm{kg}(\mathrm{n}=141)$ & All patients $(n=1104)$ \\
\hline Median SF & $(462-20788)$ & $(480-22320)$ & $(1326-16944)$ & $(462-22320)$ \\
\hline at baseline & 2356 & 3160 & 5093 & 3188 \\
\hline at EOS & 2311 & 3067 & 4167 & 3025 \\
\hline Change in SF & -45 & -93 & -926 & -163 \\
\hline$P$-value & 0.67 & 0.56 & $<0.0001$ & 0.0001 \\
\hline Mean iron intake $(\mathrm{mg} / \mathrm{kg}$ & 0.38 & 0.46 & 0.35 & 0.43 \\
\hline
\end{tabular}


cumbersome DFO infusions is considered as a major factor in mortality and morbidity. ${ }^{36}$

In fact, as late as 1999, 50\% of UK patients died before the age of 35 years and iron induced heart disease was responsible for $71 \%$ of the deaths in TM. Since 1999, there has been $71 \%$ reduction in annualized death rate from iron overload. This marked improvement in survival can be attributed to introduction of cardiac $\mathrm{T} 2 *$ to identify myocardial siderosis and appropriate intensification of iron chelation treatment. ${ }^{37}$

\section{Impact of chelator regimens on cardiac iron content}

Iron induced cardiac failure and arrhythmia is responsible for most of the deaths in TM. ${ }^{36,37}$ Assessment of cardiac iron by using magnetic resonance technique $\left(\mathrm{T} 2{ }^{*}\right)$ demonstrated that there was a progressive and significant decline in left ventricular ejection fraction below a myocardial T2* of $20 \mathrm{~ms} .{ }^{38}$ Further, it was demonstrated the impact of cardiac $\mathrm{T} 2 *$ for prediction of cardiac complications. Cardiac T2* was found superior to serum ferritin and liver iron in identifying patients at high risk of developing heart failure and arrhythmia from myocardial siderosis in TM. ${ }^{39}$ Assessment of cardiac iron by the magnetic resonance procedure and management of TM patients by considering cardiac risks is strongly recommended in clinical practice.

From that point of view, a prospective randomized study comparing standard doses of DFP and DFO, a significant reduction in cardiac iron content achieved by both chelation regimens while iron reduction in the liver was only significant in DF0 group (Table 5). ${ }^{40}$

In another randomized prospective 1 year study, the higher doses of DFP were compared with standard dose of DFO in TM patients with moderate cardiac siderosis. Although, LIC fell less impressively with DFP compared to DFO, the improvement in myocardial T2* and LVEF at 12 months was significantly greater in the patients taking DFP rather than DFO (Table 6).$^{41}$ It is assumed that transfusional iron initially fills the liver and cardiac iron may not decrease until liver iron is lowered. In contrast, based on this observation, it could be suggested that, DFP may lower cardiac iron with less reduction in liver iron.

Since DFP is less effective in removing liver iron than DFO, for simultaneously focusing on liver and heart iron combined therapy of daily DFP $75 \mathrm{mg} / \mathrm{kg} / \mathrm{d}$ plus DF0 $35 \mathrm{mg} / \mathrm{kg} / \mathrm{d} 5$ days a week has been compared in a randomised placebo control study with standard DFO monotherapy ( $43 \mathrm{mg} / \mathrm{kg} / \mathrm{d}$ x $5 \mathrm{~d} / \mathrm{w}$; equivalent $30 \mathrm{mg} / \mathrm{kg} / \mathrm{d}$ for $7 \mathrm{~d} / \mathrm{w}$ ) in TM patients with moderate cardiac siderosis. Myocardial T2* and liver T2* showed a significantly larger improvement in the combined group compared with the DFO group ( $\mathrm{p}<0.02$ and $\mathrm{p}<0.001$ respectively) (Table 7). ${ }^{42}$

Clinical studies have shown that myocardial iron removal is a slow process compared to faster removal of iron from the liver. The EPIC cardiac sub-study was designed to assess the efficacy of DFX over 3 years treatment in reducing myocardial iron in patients with TM with mild, moderate and severe myocardial siderosis as well as severe liver iron $(28.4 \pm 9.7 \mathrm{mg} / \mathrm{g} \mathrm{dw})$. Patients were initiated on $30 \mathrm{mg} / \mathrm{kg} / \mathrm{d}$ DFX and dose adjustments were allowed based on serum ferritin trends and 6 monthly cardiac T2* assessments. At end of study, $42 \%$ of patients have been receiving DFX doses of at or above $40 \mathrm{mg} / \mathrm{kg} /$ day indicating that DFX doses of above $30 \mathrm{mg} / \mathrm{kg}$ are required for cardiac iron removal. There were no deaths during the 3 year study. A continuous and significant improvement in myocardial $\mathrm{T} 2 *$ from baseline was observed in TM patients with mild to moderate and severe cardiac iron loading $(\mathrm{p}<0.001)$, along with a significant decrease in liver iron with a manageable safety profile over 3 years at these higher doses of DFX. It was notable that $68.1 \%$ of patients with mild to moderate myocardial siderosis at baseline (cardiac T2* $10-<20$ ) had normalized myocardial iron content ( $\geq 20 \mathrm{~ms}$ ) whereas myocardial iron in $50 \%$ of patients with severe cardiac siderosis (cardiac $\mathrm{T} 2 *>5-<10 \mathrm{~ms}$ ) improved to mild to moderate range after 3 years. ${ }^{43}$

Table 5. Changes in liver iron and cardiac iron content with standard doses of DFP vs DFO (Data from Maggio A, et al. Blood Cells, Molecules, and Diseases 2002; 196-208).

\begin{tabular}{|c|c|c|c|c|c|c|}
\hline \multirow[t]{2}{*}{$\begin{array}{l}\text { Chelators } \\
\text { Doses }\end{array}$} & \multicolumn{3}{|c|}{$\begin{array}{l}\text { DFP group }(\mathrm{n}=60) \\
75 \mathrm{mg} / \mathrm{kg} / \mathrm{day}\end{array}$} & \multicolumn{3}{|c|}{$\begin{array}{c}\text { DF0 group ( } \mathrm{n}=66) \\
50 \mathrm{mg} / \mathrm{kg} / \mathrm{d} \times 5 \text { days / week }\end{array}$} \\
\hline & Baseline & EOS & Difference & Baseline & EOS & Difference \\
\hline Liver MRI (SIR) & $0.83 \pm 0.21$ & $0.90 \pm 0.26$ & $-0.07 \pm 0.38$ & $0.87 \pm 0.34$ & $1.02 \pm 0.33$ & $-0.15 \pm 0.27^{\#}$ \\
\hline Heart MRI (SIR) & $1.08 \pm 0.19$ & $1.19 \pm 0.31$ & $-0.11 \pm 0.33^{*}$ & $0.96 \pm 0.26$ & $1.09 \pm 0.28$ & $-0.13 \pm 0.31^{\#}$ \\
\hline
\end{tabular}

${ }^{*} \mathrm{p}>0.05,{ }^{"} \mathrm{p}<0.01$ compared to baseline, SIR; signal intensity ratio

Table 6. Descriptives of study group at baseline and the change in LIC, myocardial T2* and LVEF at the end of study (Data from Pennell, D. J. et al. Blood 2006;107: 3738-3744).

\begin{tabular}{|c|c|c|}
\hline $\begin{array}{l}\text { Chelators } \\
\text { Dose }\end{array}$ & $\begin{array}{l}\text { DFP (n=29) } \\
92 \mathrm{mg} / \mathrm{kg} / \mathrm{d}\end{array}$ & $\begin{array}{c}\text { DFO (n=32) } \\
43 \mathrm{mg} / \mathrm{kg} / \mathrm{d} X 5,7 / \mathrm{w} \\
(35 \mathrm{mg} / \mathrm{kg} / \mathrm{d})\end{array}$ \\
\hline Compliance (\%) & $94 \pm 5.3$ & $93 \pm 9.7$ \\
\hline Transfusion (ml/kg/y) & $152 \pm 43.4$ & $144 \pm 44.4$ \\
\hline Baseline heart T2* (ms) & 13 & 13.3 \\
\hline Baseline LIC (mg/g dw) & $6.16 \pm 6.0$ & $6.32 \pm 5.8$ \\
\hline Change in LIC at EOS (\%) & -10.1 & -24.4 \\
\hline Change in T2* at EOS (\%) & +27 & +13 \\
\hline Absolute change in LVEF & $3.1 \% \pm 3.6 \%$ & $0.32 \% \pm 3.4 \%$ \\
\hline
\end{tabular}

Table 7. Description of the study group at baseline and the change in liver and myocardial $\mathrm{T}^{*}$ at the end of study (Data from Tanner MA, et al. Circulation. 2007; 115:1876-84).

\begin{tabular}{|c|c|c|}
\hline $\begin{array}{l}\text { Chelators } \\
\text { Dose (DFP) } \\
\text { Dose (DFO) }\end{array}$ & $\begin{array}{c}\text { Combined (n=32) } \\
75 \mathrm{mg} / \mathrm{kg} / \mathrm{d} \\
35 \mathrm{mg} / \mathrm{kg} / \mathrm{dX} 5,7 / \mathrm{w}\end{array}$ & $\begin{array}{c}\text { DFO (n=33) } \\
- \\
43 \mathrm{mg} / \mathrm{kg} / \mathrm{d} \mathrm{X5} / \mathrm{w} \\
(30 \mathrm{mg} / \mathrm{kg} / \mathrm{d})\end{array}$ \\
\hline Transfusion (ml/kg/y) & $133.4 \pm 34.9$ & $130.2 \pm 38.6$ \\
\hline Baseline heart T2* (ms) [>20] & 11.7 & 12.4 \\
\hline Baseline liver T2* (ms) ) [>19] & 4.9 & 4.2 \\
\hline Change in liverT2* at EOS (ms) & +5.8 & +0.8 \\
\hline Change in heart $\mathrm{T}^{*}$ at EOS (ms) & +6 & +3.3 \\
\hline
\end{tabular}




\section{How quickly can cardiac iron levels be safely removed and normalized?}

The best improvement in cardiac $\mathrm{T} 2 *$ was achieved by continuous iv DF0 chelation at a mean dose of $43 \mathrm{mg} / \mathrm{kg} /$ day which was given over 24 h, 7 day a week. In this study, all patients had T2* below $10 \mathrm{~ms}$ associated with impaired left ventricular ejection fraction at baseline. The cardiac T2* increasing on average by $4.9 \%$ per month was observed during DFO infusion of 12 months. Further, a progressive and significant improvement in LVEF over the course of intravenous treatment was also observed. ${ }^{44}$ In another prospective study, combined therapy of daily DFP $(73.9 \pm 4.0 \mathrm{mg} / \mathrm{kg} / \mathrm{d})$ and s.c. DFO $(38.0 \pm 10.2 \mathrm{mg} / \mathrm{kg} / \mathrm{d} 5.3$ days a week) has been prescribed to TM patients with similar characteristics to that reported in previous study. In this study, the improvement in cardiac $\mathrm{T}^{*}$ was almost similar with $24 \mathrm{~h}$ DF0 infusion. ${ }^{45}$ Combined therapy of DFP and DFO was also resulted with similar improvement in cardiac T2* in patients with mild to moderate myocardial iron loading. ${ }^{42}$ Overall improvement rates of cardiac T2* were comparable in other monotherapies with DFO, DFP and DFX. ${ }^{41,42,43}$

\section{Potential chelation regimens for removing cardiac iron faster than monotherapies}

It has been shown that treating heavily iron-loaded patients with intensive chelation of $24 \mathrm{~h}$ DFO infusion or combined therapy of DFP \& DF0 may rapidly decrease cardiac iron burden, thereby reducing their risk status quicker. ${ }^{44}, 45$ It would be suggested that the shuttle mechanism between DFP and DFO, ${ }^{46}$ is also likely to occur for the combination of DFX and DFO. Preliminary data showed that this combination is well tolerated in patients with TM. ${ }^{47}$ A prospective study combining DFX \& DFO in patients with severe cardiac siderosis has recently been started to see whether this combination would achieve faster removal of cardiac iron to relatively safe levels of $>10 \mathrm{~ms}$. Few short term observations have been reported for the tolerability and efficacy of combination of DFX \& DFP. ${ }^{48,49}$ However, more controlled studies are needed to investigate alternative chelation regimens.

\section{Impact of chelator regimens on endocrine tissues}

Despite therapeutic progress on survival and significant reduction in death from iron overload in the new millennium, ${ }^{48}$ endocrine complications remained as the most common cause of significant morbidity and impaired quality of life. ${ }^{49}$ Growth and pubertal failure are the earliest consequences of iron toxicity and are usually due to pituitary dysfunction. In pediatric patients prone to growth retardation due to severe iron overload, long-term DFX treatment for up to 5 years was found effective in maintaining normal growth progression and sexual development in parallel to continued and significant reduction in median serum ferritin levels over 5 years in all age groups. ${ }^{50}$ Normal growth and sexual maturation may be achieved by properly monitoring of iron loading and the timely starting and maintaining of iron chelation to prevent iron toxicity in TM. In a recent study, it has been suggested that intensified chelation with daily DFP (75-100 mg/kg/d) plus subcutaneous DF0 (20-60 mg/kg/d) may prevent and even reverse endocrine complications including impaired glucose metabolism, hypothyroidism and hypogonadism with a positive impact on patients' quality of life. In this study, intensive combination therapy was maintained until liver and cardiac iron assessed by MRI has been normalized. Once this purpose was achieved, dose and frequency of DFO was adjusted to avoid potential chelator toxicity. ${ }^{51}$

\section{Adverse events with current chelators}

The safety profile of the chelators is acceptable and manageable however appropriate monitoring of adverse reactions should be maintained since almost all of the side effects are reversible if determined at early stages.

Most of the toxic side effects of DFO on impaired growth and skeletal changes are observed in children when treatment started early $(<2$ years), at low body iron burden (serum ferritin $<1000 \mu \mathrm{g} / \mathrm{L}$ ) and at relatively higher doses of chelator ( $>40 \mathrm{mg} / \mathrm{kg}$ ). ${ }^{52,53} \mathrm{DFO}$ related retinopathy (loss of visual acuity, field defects, and defects in color vision) and ototoxicity (symmetric and high-frequency sensorioneural hearing loss) are also observed at higher doses of chelator at lower serum ferritin levels. ${ }^{54}$ Yersinia enterocolitica infections should be suspected in patients on DFO chelation with enterocolitis and fever that prompt antibiotic therapy might prevent life threatening sepsis and shock. ${ }^{55}$

Agranulocytosis is the most serious side effect of DFP therapy and close monitoring (7-10 daily control of WBC \& ANC) is required. The incidence of agranulocytosis (neutrophils $<0.5 \times 10^{9} / 1$ ) occurred in $0.5 \%$ of patients (an incidence 0.6 per 100 patients' year) during in a one year prospective study ${ }^{56}$ and no new cases of agranulocytosis developed during extension study for a further 3 years. ${ }^{57}$ Although most cases of agranulocytosis have occurred in the first few months of therapy, agranulocytosis in the second year of therapy has also been reported. Agranulocytosis is always reversible with discontinuation of DFP and reintroduction of DFP after an initial episode of agranulocytosis is not recommended. ${ }^{58}$ Gastrointestinal disturbances including nausea, vomiting and abdominal pain are met mainly at the first few weeks and months of the therapy and generally resolved by reducing dose, taking drug with meals and temporary supportive (anti-emetic) therapy. After resolving the symptoms, the dose is slowly increased to the target levels. Arthropathy affecting more frequently knees and ankles resolves after temporary discontinuation of the drug or reduction of the dose, at a median time of 12 days. Transient fluctuating increase in liver enzyme levels is generally normalized without any intervention. ${ }^{59}$ Some patients complain from increased appetite and weight gain with DFP chelation.

DFX has been investigated regarding safety during clinical studies which have been conducted with more than 3000 patients and some of these studies have been extended up to 5 years. Generally transient mild to moderate gastrointestinal disturbances (nausea, vomiting, abdominal pain, diarrhea and constipation) were observed in $15 \%$ of patients Skin rashes affecting almost $10 \%$ of patients are observed in first few weeks of DFX and generally transient. Transient fluctuations in liver enzymes have also occurred. During the first months of DFX treatment, mild, dose dependent, non-progressive increase in serum creatinine has been observed in one-third of patients. These creatinine increases remained within normal ranges, or resolved spontaneously with dose reduction. ${ }^{34}$ Cases of acute kidney injury have also been reported in the post-marketing surveillance of DFX in patients with advanced age, myelodysplastic syndromes, or other types of anaemia associated with severe co-morbidity like renal and hepatic impairment 60,61 but have not observed in patients with TM. High frequency hearing loss and lenticular opacities are also observed less frequently. It is recommended monthly monitorization of serum creatinine, urine protein and liver enzymes and annual auditory and ophthalmic examinations. 


\section{Summary and Conclusions}

Current chelation practices are mainly based on the transfusional iron loading rate, the existing body iron burden and the tolerability of chelator and dosing regimen aimed to maintain or reduce body iron to the safe levels by monitoring iron measures. However, uncertainties still exist about how low sustained levels of body iron should be maintained since the beginning to guarantee a lifelong complications free survival? How far body iron levels can be reduced without increasing chelator toxicity particularly in patients whose liver iron and ferritin have been depleted while cardiac siderosis remains?

\section{References}

1. Modell B, Darlison M. Global epidemiology of haemoglobin disorders and derived service indicators. Bull World Health Organ 2008;86:480-487.

2. Weatherall DJ, Clegg JB, The thalassemia syndromes. 4th ed. Blackwell Science; Oxford, England, 2001.

3. Pippard NJ, Callender ST, Warner GT, et al. Iron absorbtion and loading in thalassemia intermedia. Lancet 1979;2:819-21.

4. Hulbert ML, McKinstry RC, Lacey JL, Moran CJ, et al. Silent cerebral infarcts occur despite regular blood transfusion therapy after first strokes in children with sickle cell disease. Blood 2011;117:772-9

5. Ware RE, Helms RW. Stroke with transfusions changing to Hydroxyurea (SWITCH): A phase 3 randomized clinical trial for treatment of children with sickle cell anemia, previous stroke, and iron overload. Blood 2010;116: [abstract 844].

6. Noetzli LJ, Carson SM, Nord AS, Coates TD, Wood JC. Longitudinal analysis of heart and liver iron in thalassemia major. Blood 2008;112:2973-2978.

7. Di Tucci AA, et al. Myocardial iron overload assessment by T2* magnetic resonance imaging in adult transfusion dependent patients with acquired anemias. Haematologica 2008;93:13851388.

8. Deferiprone: Summary of product characteristics.

9. DFX: Highlights of prescribing information. Revised version 01/2010.

10. Cabantchik ZI, Breuer W, Zanninelli G, Cianciulli P. LPI-labile plasma iron in iron overload. Best Pract Res Clin Hematol 2005;18:277287.

11. De Domenico I, Ward DM, Kaplan J. Specific iron chelators determine the route of ferritin degradation. Blood 2009;114:4546-51.

12. Porter JB, Rafique R, Srichairatanakool S, et al. Recent insights into interactions of deferoxamine with cellular and plasma iron pools: implications for clinical use. Ann N Y Acad Sci 2005;1054:155-68.

13. Davis, B.A. \& Porter, J.B. Long-term outcome of continuous 24hour deferoxamine infusion via indwelling intravenous catheters in high-risk $\beta$-thalassemia. Blood 2000;95:1229-1236.

14. Anderson LJ, Westwood MA, Holden S. Myocardial iron clearance during reversal of siderotic cardiomyopathy with intravenous desferrioxamine: a prospective study using $\mathrm{T} 2 *$ cardiovascular magnetic resonance. Br. J. Haematol 2004;127:348-355

15. Porter JB, Abeysinghe RD, Hoyes KP et al. Contrasting interspecies efficacy and toxicology of 1,2-diethyl-3-hydroxypyrid-4-one, CP94, relates to different metabolism of the iron chelating site. Br. J. Haematol 1993;85:159-168.

16. Hoffbrand AV, Cohen A, Hershko C. Role of deferiprone in chelation therapy for transfusional iron overload. Blood 2003;102:17-24.
17. Glickstein H, El RB, Shvartsman M, Cabantchik ZI. Intracellular labile iron pools as direct targets of iron chelators: a fluorescence study of chelator action in living cells. Blood 2005;106:3242-3250.

18. Glickstein H, El RB, Link G, Breuer W, et al. Action of chelators in iron-loaded cardiac cells: Accessibility to intracellular labile iron and functional consequences. Blood 2006;108:3195-3203.

19. Pennell DJ, Berdoukas V, Karagiorga M, et al. Randomized controlled trial of deferiprone or deferoxamine in $\beta$-thalassemia major patients with asymptomatic myocardial siderosis. Blood 2006;107:3738-44.

20. Waldmeier F, Bruin GJ, Glaenzel U, et al. Pharmacokinetics, metabolism, and disposition of deferasirox in $\beta$-thalassemic patients with transfusion-dependent iron overload who are at pharmacokinetic steady state. Drug Metab Dispos 2010;38:808-16.

21. Pennell DJ, Porter JB, Cappellini MD, et al. Continued improvement and normalization of myocardial $\mathrm{T} 2 *$ in patients with $\beta$-thalassemia major treated with Deferasirox (Exjade®) for up to 3 Years. ASH 2010. Blood 2010;116:abst 4276.

22. Olivieri NF, Koren G, Harris J, et al. Growth failure and bony changes induced by deferoxamine. Am J Ped Hematol Oncol 1992;14:48-56

23. Cartwright GE, Edwards CQ, Kravitz K, et al. Hereditary hemochromatosis: phenotypic expression of the disease. N Engl J Med 1979:301:175-9.

24. Brittenham GM, Farrell DE, Harris JW, et al. Magnetic-susceptibility measurement of human iron stores. $N$ Engl J Med 1982;307:1671.

25. Porter JB, Jaswon MS, Huehns ER, et al. Desferrioxamine ototoxicity: evaluation of risk factors in thalassaemic patients and guidelines for safe dosage. Br J Haematol 1989;73:403-9.

26. Cohen AR, Glimm E, Porter JB. Effect of transfusional iron intake on response to chelation therapy in $\beta$ thalassemia major. Blood 2008;111:583-7.

27. Grady RW, Berdoukas VA, Rachmilewitz EA, et al. Iron chelation therapy: Metabolic aspects of combining Deferiprone and Desferrioxamine S.0.S.T.E. 2001;74-78.

28. Giardina PJ, Grady RW. Chelation therapy in $\beta$-thalassemia: An optimistic update. Semin Hematol 2001;38:360-6.

29. Aydinok Y, El-Beshlawy A, von Orelli-Leber C, et al. A randomized controlled trial comparing the combination therapy of Deferiprone (DFP) and Desferrioxamine (DF0) versus DFP or DF0 monotherapy in patients with thalassemia major. Blood 2006;108:abstract 557.

30. Aydinok Y, Ulger Z, Nart D, et al. A randomized controlled 1-year study of daily deferiprone plus twice weekly desferrioxamine compared with daily deferiprone monotherapy in patients with thalassemia major. Haematologica 2007;92:1599-606.

31. El-Beshlawy A, Manz C, Naja M, et al. Iron chelation in thalassemia: combined or monotherapy? The Egyptian experience. Ann Hematol 2008;87:545-550.

32. Cappellini MD, Porter J, El-Beshlawy A, et al. Tailoring iron chelation by iron intake and serum ferritin: the prospective EPIC study of deferasirox in 1744 patients with transfusion-dependent anemias. Haematologica 2010;95:557-66.

33. Taher A, El-Beshlawy A, Elalfy MS, et al. Efficacy and safety of deferasirox, an oral iron chelator, in heavily iron-overloaded patients with $\beta$-thalassaemia: the ESCALATOR study Eur J Haematol 2009;458-65.

34. Cappellini MD, Cohen A, Piga A, et al. Aphase 3 study of deferasirox (ICL670), a once-daily oral iron chelator, in patients with $\beta$-thalassemia. Blood 2006;107:3455-3462.

35. Cappellini MD, Bejaoui M, Agaoglu L, et al. Iron chelation with deferasirox in adult and pediatric patients with thalassemia major: efficacy and safety during 5 years' follow-up. Blood 2011; May 31 . 
36. Borgna-Pignatti C, Rugolotto S, De Stefano P, et al. Survival and complications in patients with thalassemia major treated with transfusion and deferoxamine Haematologica 2004;89:1187-93.

37. Modell B, Khan M, Darlison M. Survival in $\beta$-thalassemia major in the UK: data from the UK Thalassemia Register. Lancet 2000;355:2051-52.

38. Anderson LJ, Holden S, Davis B, et al. Cardiovascular T2-star (T2*) magnetic resonance for the early diagnosis of myocardial iron overload. Eur Heart J. 2001;22:2171-79.

39. Kirk P, Roughton M, Porter JB, et al. Cardiac T2* magnetic resonance for prediction of cardiac complications in thalassemia major. Circulation 2009;17;120:1961-8.

40. Maggio A, D’Amico G, Morabito A, et al. Deferiprone versus Deferoxamine in Patients with Thalassemia Major: A Randomized Clinical Trial. Blood Cells, Molecules, and Diseases 2002;196-208.

41. Pennell, DJ, Berdoukas V, Karagiorga M, et al. Randomized controlled trial of deferiprone or deferoxamine in $\beta$-thalassemia major patients with asymptomatic myocardial siderosis. Blood 2006;107:3738-3744.

42. Tanner MA, Galanello R, Dessi, C. et al. A Randomized, PlaceboControlled, Double-Blind Trial of the Effect of Combined Therapy With Deferoxamine and Deferiprone on Myocardial Iron in Thalassemia Major Using Cardiovascular Magnetic Resonance. Circulation 2007;115:1876-84.

43. Pennell DJ, Porter JB, Cappellini MD, et al. Continued improvement and normalization of myocardial T2* in patients with $\beta$-thalassemia major treated with Deferasirox (® Exjade) for up to 3 years. Blood 2010;116:abstract 4276 .

44. Anderson LJ, Westwood MA, Holden S, et al. Myocardial iron clearance during reversal of siderotic cardiomyopathy with intravenous desferrioxamine: a prospective study using $\mathrm{T} 2 *$ cardiovascular magnetic resonance Br J Haematol 2004;127:348-55.

45. Tanner MA, Galanello R, Dessi C, et al. Combined chelation therapy in thalassemia major for the treatment of severe myocardial siderosis with left ventricular dysfunction. J Cardiovasc Magn Reson 2008;10:12.

46. Link G, Konijn AM, Breuer W, et al. Exploring the "iron shuttle" hypothesis in chelation therapy: effects of combined deferoxamine and deferiprone treatment in hypertransfused rats with labeled iron stores and in iron-loaded rat heart cells in culture. J Lab Clin Med 2001;138:130-8.

47. Lal A, Nancy Sweeters PNP, Vivian NG, et al. Combined Chelation Therapy with Deferasirox and Deferoxamine In TransfusionDependent Thalassemia. Blood 2009;114 abstract 4269.
48. Modell B, Khan M, Darlison M, et al. Improved survival of thalassaemia major in the UK and relation to $\mathrm{T} 2 *$ cardiovascular magnetic resonance. J Cardiovasc Magn Reson 2008;10:42.

49. Gamberini MR, De Sanctis V, Gilli G. Hypogonadism, diabetes mellitus, hypothyroidism, hypoparathyroidism: incidence and prevalence related to iron overload and chelation therapy in patients with thalassaemia major followed from 1980 to 2007 in the Ferrara Centre. Pediatr Endocrinol Rev 2008;6:158-69.

50. Aydinok Y, Agaoglu L, Bejaoui M, et al. Growth and development of paediatric patients with $\beta$-thalassaemia treated with DFX for up to 5years. Haematologica 2010;95:429.

51. Farmaki K, Tzoumari I, Papa C, et al. Normalisation of total body iron load with very intensive combined chelation reverses cardiac and endocrine complications of thalassaemia major. $\mathrm{Br} \mathrm{J}$ Haematol, 2009;148,466-475.

52. De Virgillis S, Congia M, Frau F, et al. Desferrioxamine-induced growth retardation in patients with thalassaemia major. J Pediatr 1988;113:661-9.

53. Piga A, Luzzatto L, Capalbo P, et al. High dose desferrioxamine as a cause of growth failure in thalassaemic patients. Eur J Haematol 1988;40:380-1.

54. Olivieri NF, Buncic JR, Chew E, et al. Visual and auditory neurotoxicity in patients receiving subcutaneous deferoxamine infusions. N Engl J Med 1986;314:869-73.

55. Cherchi GB, Pacifico L, Cossellu S, et al. Prospective study of Yersinia enterocolitica infection in thalassemic patients. Pediatr Infect Dis J 1995;14:579-84.

56. Cohen AR, Galanello R, Piga A et al. Safety profile of the oral iron chelator deferiprone: a multicenter study. British Journal of Haematology 2000;108:305-312.

57. Cohen A, Galanello R, Piga A et al. Safety and effectiveness of longterm therapy with the oral iron chelator deferiprone. Blood 2003;102:1583-1587.

58. Hoffbrand AV. Deferiprone therapy for transfusional iron overload. Best Practice \& Research Clinical Haematology 2005;18:299-317.

59. Hofbrand AV, Cohen A, Hershko C. Role of deferiprone in chelation therapy for transfusional iron overload. Blood 2003;102:17-24.

60. Brosnahan G, Gokden N, Swaminathan S. Acute interstitial nephritis due to deferasirox: a case report. Nephrol Dial Transplant 2008;23: 3356-8.

61. Grange S, Bertrand DM, Guerrot D, et al. Acute renal failure and Fanconi syndrome due to deferasirox. Nephrol Dial Transplant 2010;25: 2376-8. 